\title{
Crisis neoliberal y la formulación de nuevas teorías sociales. Valor compartido y Buen vivir
}

\author{
Neoliberal crisis and the proposal of new social theories: \\ Shared value and good living \\ Crise neoliberal e a formulação de novas teorias sociais: \\ Valor compartilhado e Bom viver
}

Recibido el 28 de marzo de 2015. Aceptado el 20 de agosto de 2015

\author{
Lorena Martínez Zavala* \\ México \\ Arturo Martínez Zavala** \\ México
}

Para citar este artículo:

Martínez Zavala, Lorena

y Martínez Zavala, Arturo

(diciembre, 2015). Crisis neoliberal y la formulación de nuevas teorías sociales. Valor compartido y Buen vivir. Ánfora,

22(39), 19-43. Universidad Autónoma de Manizales. ISSN 0121-6538.

\section{Resumen}

Objetivo: identificar la repercusión que tienen las crisis generadas por el sistema neoliberal en la construcción epistemológica de las Ciencias Sociales. Metodología: investigación cualitativa en la que se utilizó el trabajo documental y el método hermenéutico con base, principalmente, en una lectura diacrónica de los documentos y en el análisis crítico de éstos. Las categorías en las que se centró el estudio fueron: "crisis del sistema neoliberal", "movimientos sociales anti neoliberales" y "giro epistemológico". Resultados: las luchas y demandas populares generadas por las limitaciones del sistema neoliberal repercuten en las reflexiones y formulaciones teóricas en el continente americano.

\footnotetext{
** Doctora en Sociología. Profesora Investigadora tiempo completo de la Facultad de Psicología de la Benemérita Universidad Autónoma de Puebla, Puebla, México. Correo electrónico: caramelo108@ hotmail.com.

** Doctor en Biotecnología. Director General de GENOMA EMPRESARIAL SA DE CV. Consultoría estratégica en Biotecnología, Innovación, Desarrollo Tecnológico y Negocios. Correo electrónico: ge@ genomaempresarial.com
} 
Conceptual o científicamente se están desarrollando teorías sociales que proponen otras estrategias de organización social. Conclusiones: se concluye que las fracturas o cambios en la estructura social del sistema impactan el pensar teórico y la construcción del conocimiento científico. La crisis financiera de 2008 en Estados Unidos generó una serie de movilizaciones sociales que surgieron como protesta ante los desajustes económicos y de empleo que desencadenó dicha crisis. En el caso de Latinoamérica, las limitaciones del sistema neoliberal para generar una adecuada calidad de vida en la población provocaron el surgimiento de movimientos antineoliberales en Ecuador, Venezuela, Bolivia y México; los cuales -excluyendo el caso mexicano- se instauraron como hegemónicos en los países donde ocurrieron. Los procesos políticos, sociales y económicos que surgieron en Norteamérica y en Latinoamérica impactaron en la construcción teórica y en la episteme predominante.

Palabras clave: Crisis neoliberal; Nuevas teorías sociales; Valor compartido; El buen vivir.

\section{Abstract}

Objective: to identify the impact of the crises generated by the neoliberal system in the epistemological construction of Social Sciences. Methodology: qualitative research that used documentary work and the hermeneutical method based on, mainly, on a diachronic reading and critical analysis of documents. The main categories of the study were "crisis of the neoliberal system", "anti- neoliberal social movements" and "epistemological turn". Results: struggles and popular requests generated by the neoliberal system limitations affect reflections and theoretical proposals in America. Conceptually or scientifically, social theories that propose other strategies of social organization are developing. Conclusions: fractures or changes in the social structure of the system impact the theoretical thinking and construction of scientific knowledge. The financial crisis of 2008 in the United States generated a series of social movements that emerged to protest against employment and economic imbalances and triggered the crisis. In the case of Latin America, the limitations of the neoliberal system to generate an adequate quality of life in the population led to the creation of antineoliberal movements in Ecuador, Venezuela, Bolivia and Mexico. Those movements were established as hegemonic in these countries except Mexico. The political, social and economic processes that emerged in North America and Latin America impacted the theoretical construction and the dominant episteme.

Keywords: Neoliberal Crisis, New social theories, Shared value, Good living. 


\section{Resumo}

Objetivo: identificar a repercussão que tem as crises geradas pelo sistema neoliberal na construção epistemológica das Ciências Sociais. Metodologia: pesquisa qualitativa na que se utilizou o trabalho documental o método hermenêutico com base, principalmente, em uma leitura diacrónica dos documentos e na análise crítica destes. As categorias nas que se centrou o estúdio foram: "crise do sistema neoliberal", "movimentos sociais anti-neoliberais" e "giro epistemológico". Resultados: As lutas e demandas populares geradas pelas limitações do sistema neoliberal repercutem nas reflexões e formulações teóricas no continente americano. Conceitual ou cientificamente estão se desenvolvendo teorias sociais que propõem outras estratégias de organização social. Conclusões: conclui-se que as fraturas ou mudanças na estrutura social do sistema impactam no pensamento teórico e na construção do conhecimento científico. A crise financeira do ano 2008 nos Estados Unidos gerou uma série de mobilizações sociais que surgiram como protesta ante os desajustes económicos e de emprego que desencadeou a crise. No caso da Latino América, as limitações do sistema neoliberal para gerar uma adequada qualidade de vida na população provocaram o surgimento de movimentos anti-neoliberais no Equador, Venezuela, Bolívia e México; os quais - excluindo o caso mexicano- se instauraram como hegemónicos nos países onde ocorreram. Os processos políticos, sociais e económicos que surgiram no Norte e Latino América impactaram na construção teórica e na episteme predominante.

Palavras-chave: Crise neoliberal; Novas teorias sociais; Valor compartilhado; $\bigcirc$ bom viver. 


\section{Introducción}

El 26 de marzo de 1975 en la Universidad Diego Portales en Santiago de Chile, Milton Friedman ofreció una conferencia en la que analizó la situación económica de Chile y emitió consideraciones sobre las posibles políticas que se podían aplicar en la región para superar los problemas económicos que atravesaba el país.

De acuerdo con la valoración de Friedman (1975, p. 17), en Chile se presentaban dos problemas centrales. En primer lugar, controlar la inflación y, en segundo, consolidar una economía fundamentada en un mercado fuerte que impulsara el desarrollo del país. Sobre el problema de la inflación, Friedman señaló que la única solución existente consistía en restringir el ingreso del gobierno. Sobre el segundo aspecto, sostuvo de manera enfática que el libre mercado era el sistema más adecuado para generar desarrollo.

Para Friedman la situación económica de Chile se superaría estableciendo una economía basada en el mercado privado, lo cual requería aplicar dos políticas importantes. En primer lugar, eliminar la ley que sostenía que un trabajador no podía ser despedido si había laborado por más de seis meses; es decir, la propuesta que hizo Friedman a los gobernantes chilenos fue flexibilizar el convenio laboral para que las empresas pudieran contratar y despedir a los empleados con mayor simplicidad. De igual manera, sugirió cambios que redujeran o eliminaran los frenos legales instituidos para regular a las empresas privadas.

Para el economista español Antonio Argandoña (1990), Milton Friedman:

[Era] un defensor apasionado de la libertad, primero de la libertad económica, pero también de todas las libertades, porque la libertad es una e indivisible. [...] Su aportación fue algo más que un alegato político, ofreciendo una alternativa basada en la libertad, en la cooperación voluntaria y en la dispersión del poder a través del mercado y de la sociedad civil (p. 4).

Treinta y nueve años después, se puede observar que dichas políticas económicas -que conforman el llamado sistema neoliberal- no sólo se aplicaron en Chile sino en gran parte del mundo. El término neoliberalismo surgió en 1938 entre un grupo de pensadores que se reunieron en el coloquio de Walter Lipmann para referirse a una doctrina económica y a un proyecto político que promovía "la propiedad privada, los mercados desregulados, el individualismo y la obtención de beneficios económicos” (Solimano, 2013). Dicha doctrina 
comenzó a instaurarse en Chile durante la década de los setenta. Posteriormente, en la década de los ochenta, se aplicó en Estados Unidos e Inglaterra; y en la década de los noventa en América Latina.

El neoliberalismo se sustenta en postulados del liberalismo económico del siglo XVIII y XIX, como: 1) El pensamiento desarrollado por Adam Smith, David Hume y John Locke sobre la importancia de promover la libertad individual. 2) Los postulados de Bentham, Walras, Jevons, Pareto y Marshall referentes al equilibrio de los mercados. 3) Las teorías de Menger, Bohm Bawer, Von Mises y Federich Hayek sobre las "teorías del capital y los ciclos, el rol de la información dispersa en la sociedad, los límites de la planificación y la preponderancia de las acciones individuales en la generación de resultados sociales" (Solimano, 2013; Von Werlhof, 2001, p. 106).

David Harvey (2007) explica claramente que:

El neoliberalismo es, ante todo, una teoría de prácticas político-económicas que afirma que la mejor manera de promover el bienestar del ser humano, consiste en no restringir el libre desarrollo de las capacidades y de las libertades empresariales del individuo, dentro de un marco institucional caracterizado por derechos de propiedad privada, fuertes mercados libres y libertad de comercio (p. 8).

Ornelas (2001) sostiene que "El neoliberalismo se propone, explícitamente, alcanzar a través del libre funcionamiento del mercado la máxima eficiencia productiva y la asignación óptima de los factores de la producción, nunca la satisfacción de necesidades sociales (p. 21). El neoliberalismo promueve libertad económica frente al Estado; es decir que éste deja de fungir como el regulador e interventor de dicha actividad económica. La injerencia del Estado no se convierte en un proceso laissez faire, pues en el sistema neoliberal se reconocen ciertas funciones esenciales que debe desempeñar, como garantizar y resguardar la propiedad privada (Hayek, 2008, p. 64; Cardoso, 2006, p. 186; Ornelas, 2001, p. 18).

El Estado instaura reglas que garanticen la libertad del individuo dentro de este juego de mercado. Tales reglas del juego, de acuerdo con Dávalos (2008), "no vienen desde fuera de las sociedades, sino que, por el contrario, las constituyen históricamente y nacen desde su interior". Estas reglas impiden la formación de monopolios, los cuales deben evitarse, ya que al igual que los subsidios impiden la óptima organización del sistema. El juego del mercado ofrece libertad al individuo, pues en éste se genera la oferta y el acceso al trabajo y la circulación de las mercancías (Dávalos, 2008; Ornelas, 2001, p. 16). 
El sistema neoliberal sostiene que la propiedad privada es el elemento central que avala la libertad de los individuos. En el mercado libre, las personas serán capaces de satisfacer sus necesidades, convirtiéndose en consumidores. Para Hayek (1976) "el juego del mercado mejoró las oportunidades de todos. [...] Practicar este juego no garantiza un nivel de ingresos específico, lo que no significa que el resultado sea injusto” (p. 181).

Friedrich Hayek (1976), uno de los máximos representantes del neoliberalismo, llevó a cabo una profunda reflexión sobre la justicia que puede existir en un sistema determinado por el mercado, siendo ésta la principal puntualización de los opositores al neoliberalismo. Sobre dicho aspecto, Hayek (1976, p. 183) señala que el término justicia social, hace referencia a una justicia distributiva; sin embargo, desde su punto de vista, no puede hablarse de justicia distributiva en un sistema en el cual no hay nadie que distribuya. El mercado es el ámbito libre en el que los individuos, a partir de sus potencialidades, son capaces de satisfacer sus necesidades. El mercado es para Hayek (1976) "una contienda jugada de acuerdo a reglas y decidida por destreza superior, fuerza o buena fortuna. [...] un juego de habilidad como un juego de oportunidad, [...] del cual cada uno ganará una cuota incierta” (p. 185).

De manera sintética, Samour(2014) establece cinco puntos rectores del sistema neoliberal. En primero lugar, el neoliberalismo promueve el individualismo y defiende la propiedad privada. En segundo, los seres humanos son concebidos como seres aplacados por las normas y tradiciones. Tercero, los seres humanos son desiguales por naturaleza y sólo existe igualdad ante el mercado y la ley. Cuarto, sostienen que la libertad es individual y sólo económica. Quinto, “el neoliberalismo en cuanto exige la sumisión de los individuos al mercado y sus leyes, cae en un individualismo autocontradictorio" (p. 605).

Estas formulaciones neoliberales se materializaron en 1989 con el Consenso de Washington. Dicha estrategia se conformó por diez postulados centrales: 1) Disciplina presupuestaria; 2) Cambios en las prioridades del gasto público; 3) La reforma fiscal; 4) Los tipos de interés; 5) El tipo de cambio; 6) Liberalización comercial; 7) Política de apertura respecto a la inversión extranjera directa; 8) Política de privatizaciones; 9) Política desreguladora y 10) Derecho de propiedad (Casilda, 2004, p. 23). Dichos planteamientos se formularon con la finalidad de emplearse en países subdesarrollados. Su aplicación en Latinoamérica estuvo ligada al uso de la violencia y represión, ejerciendo -como señala Naomi Klein (2008) - una terapia de shock que generara docilidad en la población para aceptar 
las prácticas privatizadoras. Sin lugar a dudas, la estrategia para instaurar las políticas neoliberales fue diferente para países desarrollados y para países en desarrollo. Como se señaló anteriormente, la aplicación de éstas en los segundos, estuvo ligada a un agudo proceso de violencia ejercida por la elite neoliberal que se posicionaba como hegemónica.

La aplicación de estas políticas tenía como finalidad controlar las crisis y el endeudamiento de los países en desarrollo. Sin embargo, como señala Casilda (2004) "la cara adversa fueron los resultados desalentadores en términos de crecimiento económico, reducción de la pobreza, redistribución del ingreso y condiciones sociales" (p. 24). La promesa neoliberal quedó alejada de la realidad mundial, el neoliberalismo no ha logrado erradicar o disminuir la miseria, la desigualdad, la precariedad y el desempleo. Estas problemáticas se han agudizado $\mathrm{y}$ han generado una respuesta popular que demanda cambios sociales.

La inconformidad social -evidenciada en movilizaciones populares- ha repercutido en las reflexiones teóricas tanto en el Norte como en el Sur de América. Partiendo de esto, este estudio se propone determinar los alcances que han tenido las crisis del sistema neoliberal en la edificación epistemológica de las Ciencias Sociales. Dicho objetivo surgió a partir de la carencia de artículos que abordan dicho aspecto. Ciertos trabajos retoman estos movimientos haciendo énfasis en la ruptura social que estos han generado; sin embargo, dichos artículos no puntualizan la ruptura y el cambio epistemológico que se está generando en las Ciencias Sociales con la formulación de nuevas reflexiones teóricas.

Para realizar dicho trabajo, se retoman dos teorías sociales que surgieron en la época contemporánea. Es decir, los planteamientos del buen vivir, teoría que está surgiendo de movimientos e intelectuales latinoamericanistas y la teoría del valor compartido, la cual se está gestando e impulsando por intelectuales de la Universidad de Harvard.

Se parte de estas dos teorías porque sus propuestas representan un cambio en las reflexiones teóricas tanto sociales (el buen vivir) como organizacionales (teoría del valor compartido). Para realizar dicho análisis se establecieron límites temporales que ofrecieran el contexto social y político en el cual se generaron. Tanto la teoría del buen vivir como la teoría del valor compartido tuvieron auge en el siglo XXI; sin embargo, se demarca el periodo de estudio. En el caso de la teoría del buen vivir, se empieza con la instauración del neoliberalismo en Chile durante la década de los setenta, y posteriormente, se da un salto a los movimientos 
anticapitalistas que se generaron en Ecuador, Venezuela, Bolivia y México a partir de la década de los noventa. En cuanto a la teoría del valor compartido, se parte de la crisis económica que se generó en Estados Unidos en 2008.

También, se delimitan los movimientos sociales y políticos. Durante el periodo establecido, se generaron una diversidad de movimientos sociales; por lo cual, se retoman únicamente aquellos movimientos que protestaron en contra del neoliberalismo; es decir, movimientos que evidenciaban las limitaciones de dicho sistema y proponían modificaciones a las políticas neoliberales o cambios radicales que permitieran la instauración de otro sistema social. En síntesis, la presente investigación tiene como finalidad determinar las implicaciones que han tenido las crisis generadas en el sistema neoliberal en la construcción epistemológica de las Ciencias Sociales. Este estudio, entonces, se propuso conocer de qué manera las luchas y demandas populares están impactando en el pensar científico y en la formulación de teorías que proponen otras alternativas de organización social.

\section{Metodología}

Esta investigación se basó, fundamentalmente, en el método cualitativo. Como primer paso, se llevó a cabo un trabajo documental que permitió obtener y recopilar datos e información relevante sobre los aspectos económicos, políticos y sociales dentro de los cuales se generó la formulación de la teoría del valor compartido y la teoría del buen vivir. También se recabó información de documentos primarios, como los informes emitidos por organismos internacionales como la Comisión Económica para América Latina y el Caribe (CEPAL), artículos de revistas y libros publicados por representantes de las dos teorías sociales que apoyan esta investigación: la teoría del valor compartido y la teoría del buen vivir. De igual manera, se utilizan notas periodísticas, conferencias impresas y entrevistas.

La información recopilada se sistematizó elaborando fichas de trabajo. Posteriormente, se sometieron dichos datos al método hermenéutico, específicamente la lectura diacrónica. Retomando a Daniel Behar (2008), se entiende el método hermenéutico como "la ciencia o el arte de comprender un documento, un gesto, un acontecimiento, captando todos sus sentidos" (p. 49). A partir de esta concepción, se interpretan los diferentes síntomas de la crisis neoliberal como los puntos coyunturales que impulsaron o generaron un cambio epistemológico en las ciencias sociales. 
Con base en la concepción de Behar (2008, p. 49) sobre el uso de la lectura diacrónica, los documentos se analizaron ubicando el contexto histórico social, político y económico en el cual se gestaron. Como paso esencial de este apartado se delimitó la temporalidad de las dos teorías abordadas: la teoría del valor compartido (2008 - 2014) y la teoría del buen vivir (1970’s - 1990’s - 2014). De igual manera, se deslindaron los movimientos sociales, considerando únicamente aquellos movimientos que surgieron en contra del sistema neoliberal y que proponían modificaciones a las políticas que dicho sistema establece.

Para procesar la información se siguió la metodología sugerida por Sautu, Boniolo, Dalle y Elbert (2005, p. 84), la cual consiste en tres pasos esenciales. Como primer paso, se sintetizaron las ideas centrales sobre las cuales se basan las propuestas teóricas del valor compartido y del buen vivir. Como segundo paso, se examinaron los conceptos y propuestas centrales de ambas teorías. Y finalmente, el tercer paso consistió en analizar si dichas teorías representan verdaderamente un aporte distinto a lo sostenido por el pensamiento neoliberal.

Después de haber analizado el contenido y las propuestas de cada teoría, se seleccionó la información relativa a la situación política y económica de las regiones en las que surgieron dichas reflexiones teóricas. Esto, con el fin de establecer un proceso causal entre las crisis económicas y los movimientos contestatarios con las formulaciones y propuestas de dichas teorías. Ya obtenida esta información se analizaron los datos necesarios para concluir si dichos procesos estaban generando una crisis en la construcción científica de las Ciencias Sociales y un impulso en la formulación de teorías que responden a las necesidades actuales de la sociedad.

\section{Resultados}

La vigencia y viabilidad del neoliberalismo como un sistema social que generó bonanza, empleo, etc. está siendo debatida. Las crisis económicas y políticas que se han generado en Norteamérica y en Latinoamérica en el siglo XX y XXI evidencian un agotamiento del sistema neoliberal y un desencanto de las promesas neoliberales referentes a la generación de las condiciones necesarias para que la población viva con una óptima calidad de vida.

Esta crisis en el sistema neoliberal está impactando en la formulación y planteamientos científicos sociales que promueven alternativas teóricas a las 
planteadas por los promotores ortodoxos del neoliberalismo y del libre mercado. Es decir, existe una crisis neoliberal y una crisis de la viabilidad de las teorías sociales para entender y organizar la realidad actual (a lo largo de esta sección se desglosan los datos que respaldan esta afirmación). Estas crisis, no sólo han cimbrado al sistema neoliberal, sino también han impactado en la construcción de teorías sociales que, desde el ámbito científico, proponen otra forma de organización social y empresarial.

Los resultados se presentan así: como primer elemento, se expondrán y discutirán los efectos económicos, políticos y sociales que se han generado en Latinoamérica. En dicha región las limitaciones del sistema neoliberal generaron el estallido de movimientos políticos que buscaban instaurar un sistema social que planteara políticas distintas a las establecidas por el neoliberalismo. Dichos movimientos, como se evidenciará adelante, lograron consolidarse en el poder e instaurar un sistema político alterno al neoliberalismo, lo cual implicó un replanteamiento teórico y epistemológico de las teorías sociales.

Posteriormente, se presentarán las problemáticas y repercusiones políticas y sociales que provocó la crisis económica estadounidense en 2008. Luego, los postulados sostenidos por los teóricos del valor compartido, puntualizando aquellos rasgos que plantean una ruptura con el pensamiento neoliberal ortodoxo.

\section{El buen vivir. Contexto y propuesta}

Milton Friedman -teórico del neoliberalismo- sostenía que el libre mercado goza de las siguientes virtudes. En primer lugar, "tiene poder de asignación al permitir, mediante el intercambio, la coordinación de actividades en la producción eficiente de bienes y servicios". En segundo, "fomenta la voluntad sin la coerción"; en tercer lugar, "transmite información sin coordinación explícita"; y en cuarto, "iguala las diferencias y permite la remoción de la discriminación" (Pérez, 2001, p. 16).

El elemento central de la propuesta de Friedman es la libre elección de los individuos; dicho autor consideraba que el proteccionismo del Estado generaba ciudadanos "incapaces de ganarse la vida [...] [y una estructura $]$ corrupta y clientelista que lastraba y a veces imposibilitaba la creación de riqueza" (Pérez, 2001, p. 16). Para Friedman, la libre competencia es el núcleo del desarrollo, pues mejora los bienes y servicios. De igual manera, sostenía que la libertad es 
el principal derecho que se debe garantizar en las sociedades. Además planteaba que "una sociedad que priorice la igualdad por sobre la libertad no obtendrá ninguna de las dos cosas. Una sociedad que priorice la libertad por sobre la igualdad obtendrá un alto grado de ambas" (Montaner, 2012, p. 4).

Figueroa (2010, p. 13) plantea que los promotores del neoliberalismo señalaban que la aplicación de este sistema iba a generar prosperidad económica a través de altas tazas de productividad, estabilidad política y democracia. Sin embargo, dichas propuestas no se han cristalizado, pues el crecimiento del Producto Interno Bruto (PIB) en América Latina ha sido moderado y se ha generado inestabilidad política, pues como señala dicho autor "la realidad indica que aproximadamente 16 presidentes en el continente han sido derrocados por las rebeliones populares que han provocado las políticas económicas neoliberales".

De acuerdo con el informe Panorama Social en América Latina 2013, elaborado por la CEPAL (2013), en el 2012 el 28.2\% de la población en América Latina se encontraba clasificada en condición de pobreza, y el $11.3 \%$ en indigencia o pobreza extrema. Dichos porcentajes significan 164 millones de personas pobres, de las cuales 66 millones están clasificados en pobreza extrema.

De igual manera, la CEPAL establece que "la elevada desigualdad en la distribución de los ingresos es uno de los rasgos característicos de América Latina en el contexto internacional". La calidad de vida de los niños y adolescentes es muy precaria, pues el escaso ingreso económico de sus hogares, limita derechos esenciales como la vivienda, educación, salud y nutrición (2013, pp. 16, 19).

Otra problemática más es el empleo, pues los puestos son precarios, mal remunerados, flexibles e informales. Dicha condición laboral quebranta la creencia de que el neoliberalismo ofrece caminos y medios de movilidad o ascenso social, disminuye la esperanza de la población de vivir mejor a través de su trabajo (Dupas, 2008, p. 70).

Estas problemáticas evidencian que el neoliberalismo ahondó las desigualdades sociales, la precariedad en la calidad de vida y profundizó la inseguridad laboral. Es posible concebir que dicho sistema no conlleva un compromiso con la sociedad y su bienestar. Como acertadamente señaló Claudia Von Werlhof (2011, p. 106, 109), en el sistema neoliberal: 
La supuesta imprescindible "libertad" de la economía -que paradójicamente se reduce a la libertad de las corporaciones- comparten un quedar libre de cualquier responsabilidad y compromiso para con la sociedad. [...] El dominio de los medios de producción se ha ido concentrando cada vez más en manos de una minoría.

Las políticas económicas neoliberales y sus limitaciones para establecer sociedades más equitativas han generado el estallido de movimientos sociales que de manera contestataria buscan disolver alguna política neoliberal específica y/o instaurar un sistema económico, político y cultural distinto al existente. Como señalan Antunes y Bragas (2011), "las recetas neoliberales han venido dando signos de agotamiento y los pueblos de América Latina van ahora por delante de esos embates" (p. 159).

Según Sidney Tarrow (2004) hay periodos en los que la protesta social se presenta con mayor intensidad. A dichos momentos le denomina ciclos de movilización; los cuales son "puntos de inflexión para el cambio social y político" (p. 203). Durante el ciclo de protesta, se genera una rápida difusión de la acción colectiva, la cual expande la información innovadora de los movimientos. Este proceso influye en otros actores que poseen menos recursos, al abrir oportunidades útiles para todos los actores sociales. Además, crean nuevos marcos compartidos y una mayor interacción con las autoridades. Las primeras luchas son las que inician los grandes ciclos, desafían al poder existente, y de esta manera, muestran los límites y las debilidades del poder.

En la década de los noventa, a partir de la consolidada aplicación de las políticas neoliberales en América Latina, se generó un ciclo de movilización de gran impacto para dichas políticas y para la reestructuración de la geopolítica de la región. Como señala Blanco (2010):

Desde finales de los 90, se observa una tendencia general al incremento de la conflictividad. La conflictividad en ese periodo se concentra en la zona andina, mientras en el Cono sur se puede observar una disminución, con las excepciones de Argentina y Paraguay. Dentro de la tendencia general y fijándonos en las tendencias regionales, se puede observar coyunturas de agudización de los niveles de conflictividad social por periodos y países. Así ha ocurrido en Argentina, Bolivia, Chile, Ecuador, Honduras y Nicaragua (p. 60).

Las movilizaciones sociales en este ciclo abordan diversas demandas; se han generado movimientos políticos que buscan instaurar modificaciones 
constitucionales. De igual manera, han surgido movimientos ambientalistas, feministas, estudiantiles, de desempleados, indigenistas, defensa de derechos humanos, sindicales y campesinos. En la década de los 80 y 90, los movimientos "marginados" o "excluidos" pusieron a la mujer en el sitio clave de la demanda de bienestar de necesidades esenciales para el ser humano. En estas movilizaciones, las mujeres se organizaron para autogestionar recursos que satisficieran aspectos de alimentación, seguridad y servicio; objetivos que se pretendían alcanzar generando un "espíritu comunitario y fuertes lazos de solidaridad" (Brukmann y Dos Santos, 2008, p. 10).

La aplicación de las políticas neoliberales generó un nuevo ciclo de lucha popular. Como indican Bruckmann y Dos Santos (2008, p. 11):

Después de Seattle en 1999, los encuentros del Foro Social Mundial en Porto alegre y las manifestaciones de masa que lo sucedieron en varias partes del mundo ya se perfila una nueva realidad de los movimientos sociales, $[\ldots]$ cobra un significado especial después de la caída del campo soviético cuando las luchas sociales ganan la dimensión de un gigantesco movimiento de la sociedad civil contra la globalización neoliberal.

Sin lugar a dudas, existen un sinnúmero de movimientos sociales que han surgido en América Latina; sin embargo, se considera que son cuatro los movimientos claves por su irrupción, capacidad contestataria y cuestionadora de la viabilidad de las políticas neoliberales. Y, además de su influencia política, dichos movimientos han generado un impacto central en las reflexiones teóricas de las ciencias sociales. Es decir, los movimientos de resistencia que se generaron en Ecuador, Venezuela, Bolivia y México. Como señalan Antunes y Braga (2011), en dichas regiones se "ha empezado a diseñar una nueva forma de poder popular auto-constituyente, moldeado desde la base" (p. 160).

La movilización, organización y protesta popular ha sido un fenómeno clave en la geopolítica de la región. Entre los movimientos que hay que destacar es la movilización indígena generada en Ecuador y que dio como resultado el derrocamiento y destierro del presidente Jamil Mahuad en el año 2000. La lucha de los pueblos indígenas ecuatorianos data de los años 90 con la conformación del movimiento político Pachakutik. Dicho movimiento fue reconfigurando y replanteando sus demandas políticas. En un inicio fue un movimiento reivindicador de la tierra, posteriormente, empezó a cuestionar la estructura jurídica del Estado (Gómez Leyton, 2011, p. 10; Somuano, 2007, p. 44; Dávalos, 2004, p. 6). 
En este ciclo, Venezuela inició un proceso de demanda política que buscaba instaurar un gobierno popular. En la década de los ochenta se generó un amplio movimiento social que evidenció la crisis que atravesaba el capitalismo en países en desarrollo. Dicha movilización estalló en Caracas el 27 y 28 de febrero de 1989. El llamado “caracazo" fue resultado de una fuerte crisis económica que atravesaba el país debido a endeudamientos que contrajo entre 1975 y 1978 (deuda que aumentó de 6 mil millones de dólares a 31 mil millones), la caída de la renta petrolera (en 1973 el barril costaba 28,9 dólares, disminuyó a 10,9 dólares en 1986) y la fuga masiva de capitales (Martínez, 2008, p. 85). Ante dicha crisis, el Estado venezolano emprendió una serie de reformas económicas que protegían a la burguesía venezolana y atribuían el pago de la deuda externa a la población. Como señala Martínez (2008), "los trabajadores asalariados, los empleados públicos y los sectores populares depauperados debían cargar con las consecuencias de la dependencia y sumisión del régimen. [...] Mientras que la remuneración del trabajo (en salario) era de 61,2\% en 1960, [...] a finales de los ochenta disminuyó hasta 15\%” (p. 88).

El caracazo fue un motín de hambre que el Estado disolvió con violencia. Las fuerzas armadas irrumpieron para atenuar las movilizaciones populares y los saqueos, este operativo dejó 2.227 muertos (Martínez, 2008, p. 89). De manera inmediata pareció que la disidencia había sido controlada; sin embargo, la fractura se evidenció nuevamente años posteriores. En 1992, el Movimiento Bolivariano Revolucionario 200 (MBR-200) intentó dar un golpe de Estado contra el presidente Carlos Andrés Pérez. Ante la imposibilidad de cristalizar dicha acción, el dirigente principal, Hugo Chávez Frías, fue apresado y encarcelado durante dos años. Con el apoyo del Movimiento Quinta República se postuló para presidente de la República en las elecciones de 1998. La victoria de Chávez en el proceso electoral fortaleció el poder de los países en resistencia de América Latina (Martínez, 2014, p. 22; Lander y López, 1999, p. 9).

Los movimientos indígenas en Bolivia han sido un proceso en el que los actores luchan contra la colonización y dominación imperialista, ubicando a los indígenas como constructores y dirigentes de la política del país. La Guerra del gas en 2003, movilización que los indígenas llevaron a cabo para impedir la explotación del gas natural y la exportación de éste, generó la destitución del presidente Gonzalo Sánchez Lozada. Este primer paso, permitió el triunfo del presidente Evo Morales en las elecciones de 2005, que fue un proceso clave en el empoderamiento de los pueblos indígenas (Gómez Leyton, 2011, p. 10; Zuazo, 2010, p. 125). 
De igual manera, el levantamiento Zapatista el 1 de enero de 1994, en San Cristóbal, Chiapas, México. Dicha insurrección surgió como protesta de la instauración del Tratado de Libre Comercio de América del Norte (TLCAN). El surgimiento del EZLN fue un acontecimiento sorpresivo, pues en México parecía que el Estado había logrado disolver o aminorar los movimientos contestatarios, principalmente aquellos que luchaban por derrocar al gobierno e instaurar una sociedad distinta. México ha tenido una larga historia de surgimiento de movimientos guerrilleros que buscaban derrocar al Estado. Los movimientos guerrilleros de las décadas de los sesenta, setenta y ochenta fueron controlados y desbaratados por el Estado mexicano. En este contexto de aparente pasividad política surge el movimiento zapatista con un discurso antineoliberal y antiglobalización. Es un movimiento que rompió con la forma clásica de lucha revolucionaria e instaura un nuevo paradigma de lucha popular (Martínez y Herrera, s. f.).

Como ya se indicó, los movimientos populares en Venezuela, Ecuador y Bolivia se consolidaron como poderes hegemónicos, generando así un contrapoder a las políticas neoliberales de la región. La instauración de dichos poderes generó una serie de reflexiones políticas, económicas, filosóficas y teóricas referentes a la construcción de una sociedad distinta a la forma de organización neoliberal. A partir de estos procesos se empezó a reflexionar en un nuevo paradigma denominado el buen vivir.

Esta concepción se refiere a una convivencia armónica con la naturaleza y con el otro. Es un planteamiento crítico y contrario a la postura neoliberal, pues esta última parece instaurarse bajo una política de generar valor y plusvalía, aun devorando los recursos naturales y sin establecer soluciones a las necesidades reales de las regiones. Es decir, en el neoliberalismo los recursos naturales son extraídos de manera indiscriminada, como si fueran recursos renovables e infinitos; la cual además, no va dirigida a atenuar los problemas sociales o a generar una buena calidad de vida para la población.

Los planteamientos del buen vivir están conformados por la filosofía y la cosmovisión indígena. El presidente de Bolivia, Evo Morales (2011) lo plantea de la siguiente manera:

El Vivir Bien como una forma de vida, de relacionamiento con la naturaleza, de complementariedad entre los pueblos es parte de la filosofía y la práctica de los Pueblos Indígenas. Asimismo, no sólo desnuda las causas estructurales de las crisis 
(alimentación, climática, económica, energética) que vive nuestro plantea, sino que plantea una profunda crítica al sistema que está devorando a seres humanos y a la naturaleza: el sistema capitalista mundial (p. 9).

Posteriormente señala:

Mientras los Pueblos Indígenas proponen para el mundo el "Vivir Bien", el capitalismo se basa en el "Vivir Mejor". Las diferencias son claras: El vivir mejor significa vivir a costa del otro, explotando al otro, saqueando los recursos naturales, violando a la Madre Tierra, privatizando los servicios básicos; en cambio el Vivir Bien es vivir en solidaridad, en igualdad, en armonía, en complementariedad, en reciprocidad (Morales, 2011, p. 9).

Los postulantes del buen vivir sostienen que este planteamiento o propuesta de sociedad elimina el vicio central del neoliberalismo; el cual consiste en la búsqueda de las empresas trasnacionales por obtener lo máximo de ganancias y utilidades. Antunes y Braga (2011) plantean que el buen vivir, es una "necesidad de construir un nuevo sistema de metabolismo social, de un nuevo modo de vida fundado en la actividad autodeterminada, fuera de las reglas y constreñimientos del mercado, el dinero y del capital" (p. 164).

Las movilizaciones populares a las que se ha hecho referencia en este apartado son un síntoma de la incapacidad del sistema neoliberal para ofrecer a la población las condiciones necesarias para vivir con una adecuada calidad de vida. Estos movimientos cuestionaron el accionar político y el pensamiento teórico neoliberal; gestando la construcción teórica de un nuevo pensamiento que propone otra forma de organización.

\section{La teoria del valor compartido. El contexto socio económico en que surgió y su propuesta}

La Universidad de Harvard, además de ser considerada la mejor universidad a nivel mundial (ABC.es, 2013), es concebida como el bastión de las reflexiones neoliberales. Durante muchos años, en esta institución se planeaban las políticas públicas y económicas; sin embargo, en el siglo XXI, estos planteamientos teóricos predominantes empezaron a ser cuestionados al interior de dicha institución. Uno de los acontecimientos que evidenció esto, fue la huelga de los alumnos del curso Economía 10 el 2 de noviembre de 2011 . En esta protesta, los estudiantes manifestaron su inconformidad por las políticas neoliberales, y sobre 
todo por el impacto negativo que éstas han tenido sobre el empleo, la educación, la salud, etc. (Serrano, 2011).

La crisis de 2008 en Estados Unidos generó una ruptura en la aceptación de los ciudadanos americanos sobre la viabilidad de las políticas neoliberales. El 15 de septiembre de 2008 se anunció que el banco de inversión Lehman Brothers estaba en quiebra. Esta crisis, que al inicio parecía ser una crisis hipotecaria, se convirtió en una crisis económica que impactó en la economía mundial. Dicha crisis fue denominada "Gran recesión" de 2008, pues los efectos fueron a nivel global, impactando, no sólo en la economía de los estadounidenses, sino también, en países pertenecientes a la Organización para la Cooperación y el Desarrollo Económicos (OCDE), la cual está conformada por 34 países (Tanzi, 2010, p. 7; Laffaye, 2008, p. 44).

La crisis económica de 2008 tuvo un impacto importante en Estados Unidos; por ejemplo, el Producto Interno Bruto (PIB) de dicho país se contrajo 6.2\%. La producción industrial disminuyó $1.8 \%$. La tasa de desempleo ronda alrededor de 8.5\%, lo cual representa 5.3 millones de desempleados. Como señalan Zurita, Martínez y Rodríguez, (2009, p. 29), dicha crisis financiera se convirtió en una crisis de producción y empleo.

Las limitaciones del sistema neoliberal para instaurar una adecuada calidad de vida para la ciudadanía, no solo empezaron a generar inconformidad; sino que empezaron a permear las reflexiones teóricas formuladas por los economistas de Harvard. Porter y Kramer (2011), profesores de la Universidad de Harvard, establecieron y desarrollaron la teoría del valor compartido. Afirman que:

El sistema capitalista está bajo asedio. En los últimos años, las empresas han sido vistas cada vez más como una causa importante de los problemas sociales, ambientales y económicos. Hay una percepción muy amplia de que las compañías prosperan a costa de la comunidad (Porter y Kramer, 2011, p. 3).

Porter y Kramer (2011) plantean que socialmente se concibe a las empresas como organizaciones que buscan generar valor o lograr un desempeño económico a corto plazo, dejando de lado aspectos fundamentales como las necesidades reales de los clientes, la depredación de los recursos naturales y los problemas económicos de la comunidad. Dichos tópicos, se convierten en aspectos secundarios que únicamente se abordan desde una actitud filantrópica de la empresa, en "donde los problemas sociales están en la periferia, y no en el centro”. 
Para dichos autores, esto es un aspecto que se debe modificar en la visón empresarial, pues estas "deben asumir el liderazgo para volver a unir los negocios con la sociedad” (Porter y Kramer, 2011, p. 3). A partir de dicha problemática, surge la teoría del valor compartido, el cual se refiere a la creación de valor económico que cree un valor para la sociedad y que satisfaga sus necesidades y problemas.

Sin lugar a dudas, la teoría del valor compartido no plantea un sistema distinto al capitalismo; sin embargo, si establece la necesidad de consolidar empresas que estén vinculadas con los problemas comunitarios. Es decir, la conformación de empresas que sean parte de la solución y búsqueda de desarrollo, generando valor tanto para el sector privado, como para la población o comunidad. Como claramente señalaron Porter y Kramer (2011):

El capitalismo es un vehículo inigualable para satisfacer las necesidades humanas, mejorar la eficacia, crear trabajos y generar riqueza. Pero una concepción estrecha del capitalismo ha impedido que las empresas exploten todo su potencial para satisfacer las necesidades más amplias de la sociedad (p. 4).

Para posteriormente señalar:

Llegó el momento de una nueva concepción del capitalismo [ ...]. El propósito de la corporación debe ser redefinido: es la creación del valor compartido, no sólo las utilidades per se. Esto impulsará una nueva oleada de innovación y crecimiento de la productividad en la economía global. También le dará una nueva forma al capitalismo y su relación con la sociedad.

Porter y Kramer (2011) definen el valor compartido como "las políticas y las prácticas operacionales que mejoran la competitividad de una empresa a la vez que ayudan a mejorar las condiciones económicas y sociales en las comunidades donde operan” (p. 6). Como señala Mutis (Mutis, 2013) los planteamientos del valor compartido son una ruptura con los planteamientos tradicionales de Milton Friedman, pues combate la postura de priorizar el interés particular sobre el interés general. La propuesta del valor compartido sostiene que "las utilidades de las empresas deben ir a la par del progreso social y el desarrollo sostenible de la comunidad que debe ser promovido por dichas empresas” (p. 116).

La teoría del valor compartido sostiene que dicho valor se puede generar desarrollando tres elementos centrales. En primer lugar, re-concibiendo los productos y las mercancías. Esto se refiere a que las empresas deben replantear la 
oferta, basada en cubrir las necesidades insatisfechas de la población, generando que el mercado participe en el crecimiento y bienestar ambiental, económico y social (Fernández, 2014; Porter y Kramer, 2011, p. 7).

En segundo lugar, redefiniendo la productividad en la cadena de valor. Alude a la necesidad de optimizar las condiciones operativas al interior de la empresa, buscando reducir los costos productivos, mejorar el acceso a las materias primas, optimar las condiciones ambientales e invertir en la capacitación del personal (Fernández, 2014; Porter y Kramer, 2011, p. 8).

Finalmente, el tercer elemento consiste en el desarrollo de clusters locales. Dicha teoría parte del postulado de que ninguna empresa es autosuficiente. Más bien, como organización interconectada puede generar valor compartido estableciendo actividades cooperativas con otras instancias. El trabajo conjunto con otras empresas, instituciones, universidades, asociaciones de comercio etc. permite conectar a diversas empresas y vincular su oferta con las problemáticas sociales (Fernández, 201; Porter y Kramer, 2011, p. 12).

Podemos establecer que el surgimiento de la teoría del valor compartido en Norteamérica se gestó y fue resultado de crisis y fracturas generadas en el sistema neoliberal. Esta teoría representa una fractura, un reacomodo y un replanteamiento de la organización del sistema que busca instaurar una organización social que elimine la visión voraz del neoliberalismo y genere una triangulación enriquecedora entre Estado, empresarios y comunidad.

\section{Conclusiones}

Las limitaciones neoliberales están generando movilizaciones contestatarias e impactan la construcción científica y teórica que la sustenta; dando lugar a la formulación de nuevas teorías que proponen otras alternativas de organización y desarrollo social.

Thomas Kuhn (1995, p. 26, 28) en su prestigioso trabajo La estructura de las revoluciones científicas, estableció que el avance de la ciencia se puede generar en dos contextos: bajo el desarrollo de la ciencia normal y durante las revoluciones científicas. La ciencia se establece bajo un paradigma dominante que se instaura y sostiene con el surgimiento de teorías y conocimientos que fortalecen y sustentan dicho paradigma. En la ciencia normal se eliminan innovaciones que puedan modificar el paradigma científico. 
Ni la sociedad ni la ciencia pueden plantearse como sistemas estáticos; más bien, deben concebirse como procesos dinámicos que están en constante cuestionamiento y modificación. Esta característica genera el surgimiento de nuevas teorías científicas que desencadenan cambios en los principios que regulan y conforman la ciencia normal. De acuerdo con Kuhn (1995, p. 36) este proceso revolucionario objeta el paradigma establecido y establece un nuevo paradigma, proceso que va generando desarrollo en la ciencia.

En este estudio, entonces, se concluye que el sistema neoliberal -a partir de su instauración en la década de los setenta- se estableció como el paradigma dominante que conformó el pensamiento teórico. Las teorías y pensamientos que gozaban del reconocimiento de la comunidad científica se realizaban dentro del paradigma establecido y contribuían al desarrollo de la ciencia normal. Sin embargo, como resultado de las limitaciones del sistema neoliberal y su incapacidad para satisfacer necesidades elementales en la población, empezaron a surgir movimientos sociales que cuestionaba el sistema neoliberal; es decir, cuestionaban toda su estructura económica, social, política, económica y teórica. Dicha ruptura generó el surgimiento de nuevas reflexiones teóricas: el buen vivir y el valor compartido.

Thomas Kuhn (1995) señala que "las revoluciones políticas se inician por medio de un sentimiento [ $\ldots$.$] de que las instituciones existentes han cesado$ de satisfacer adecuadamente los problemas planteados. De manera similar, las revoluciones científicas se inician con un sentimiento creciente $[\ldots]$ de que un paradigma existente ha dejado de funcionar adecuadamente" (p. 156).

El surgimiento de movimientos antineoliberales en América Latina, la crisis de 2008 en Estados Unidos y los movimientos de protesta en contra de los efectos generados por dicha crisis, evidenciaron que el paradigma dominante estaba rebasado y limitado para explicar una nueva realidad social. Los movimientos sociales y las demandas populares, no solamente están teniendo repercusión en el desarrollo y establecimiento de las políticas neoliberales; sino que también ejercen influencia en el replanteamiento teórico y científico del continente americano.

La teoría del buen vivir y del valor compartido difieren en que la segunda sostiene dichos cambios, como planteamientos dentro del sistema capitalista y como un medio de permanencia de este. En cambio, la teoría del buen vivir tiene una postura crítica al capitalismo, planteando la necesidad de instaurar otro sistema social. Es decir, la teoría del valor compartido no genera una ruptura, sino 
un replanteamiento en las teorías que reflexionan sobre la vinculación existente entre el sector empresarial y la sociedad, cuestionando un elemento central del sistema neoliberal: la incapacidad de generar una justicia distributiva. En cambio, los planteamientos del buen vivir generaron una crisis en la epistemología. Representó una ruptura con lo existente para ofrecer un nuevo pensamiento y reflexión social. Como señala Enrique Dussel (Muñoz y Marín, 2012), estos procesos generaron un giro epistemológico que rompe con las concepciones teóricas eurocéntricas y genera una reflexión teórica latinoamericanista.

De manera concordante, la teoría del valor compartido y la teoría del buen vivir, plantean al sector empresarial tanto trasnacional como nacional, como el ámbito en el que se deben aplicar cambios fundamentales, basados principalmente en establecer empresas que satisfagan las necesidades reales de la población, que desarrollen principios basados en el desarrollo de la comunidad y que dicho desarrollo se lleve a cabo en armonía y cuidando de la naturaleza, el medio ambiente y la sustentabilidad del planeta tierra.

A pesar de que ambas teorías tienen diferencias y convergencias, las dos representan un cuestionamiento al paradigma dominante. Ambas evidencian errores en dicho paradigma y proponen el establecimiento de uno nuevo. Las dos proponen una nueva forma de pensar lo social, de explicar la realidad y de organizar el mundo.

\section{Referencias}

ABC.es, (2013). Las diez mejores universidades del mundo. Recuperado de: http:// www.abc.es/sociedad/20130817/abci-diez-mejores-universidadesmundo-201308161148_1.html

Antunes, R. y Braga, R. (2011). Para un nuevo estilo de vida en América Latina: orígenes básicos de otro sistema del metabolismo social. En Ivonne Farah H y Luciano Vasapollo (Coordinadores). Vivir Bien ¿̇Paradigma no capitalista? Bolivia: CIDES-UMSA, Sapienza, Oxfam.

Argandoña, A. (1990). El pensamiento de Milton Friedman. IESE Business School, Barcelona, España.

Behar Rivero, D. (2008). Metodología de la investigación. Bogotá: Shalom. 
Cardoso, H. A. (2006). El origen del neoliberalismo: tres perspectivas. Espacios Públicos, 9(18), 176-193. México: Universidad Autónoma del Estado de México.

Casilda, R. (2004). América Latina y el Consenso de Washington. Boletín ICE Económico, (2803).

Cepal. (2013). Panorama Social en América Latina 2013. Recuperado de: www. cepal.org/cgi_bin/getProad.asp? xml=/publicaciones/xml/9/51769/ P5/769.xml\&base=/tpl/top-bottom.xsl.

Cortés, G. y García, S. (2003). Investigación documental. Guía de autoaprendizaje. México: ENBA.

Dávalos, P. (2008). Neoliberalismo político y Estado social de derecho. América Latina en Movimiento. Recuperado de: www.alainet.org/es/active/24785.

Dávalos, P. (2004). Movimiento indígena ecuatoriano: La construcción de un actor político. Disponible en: icc.nativeweb.org/papers/davalos 1.pdf.

Dupas, G. (2009). Pobreza, desigualdad y trabajo en el capitalismo global. Nueva Sociedad, No 215, Mayo-Junio. Recuperado de: www.nuso.org/upload/ articulos/3522_1.pdf

Fernández, R. (2014). El valor compartido, una evolución de la RSE. Diario responsable. Recuperado de: www.diarioresponsable.com/portada/opinion/1701 1-el-valor-compartido-una evolución-de-la-rse.html.

Figueroa, C. (2010). ¿En el umbral del posneoliberalismo? Izquierda y gobierno en América Latina. Guatemala: FLACSO-Guatemala / F\&G Editores.

Friedman, M. (1975). Milton Friedman en Chile. Bases para un desarrollo económico. En Versión de la conferencia pública ofrecida por el Dr. Milton Friedman en el Edificio Diego Portales de Santiago, el 26 de marzo de 1975. Recuperado de: http://www.elcato.org/pdf_files/mfriedman-confchile-1975.pdf.

Gómez, J. C. (2011). Protesta política y poder constituyente: No invocamos tu nombre en vano'. América Latina 12. Santiago de Chile: Arcis. 
Harvey, D. (2007). Breve historia del neoliberalismo. Recuperado de: https:// derechoterritorio.files.wordpress.com/2014/09/breve-historia-delneoliberalismo-_-david-harvey-espac3b1ol.pdf.

Hayek, F. (2008), Camino de servidumbre: Textos y documentos. España: Liberty Fund, El Cato.org, Unión Editorial.

Hayek, F. (1976). El atavismo de la justicia social. The 9th R.C. Mills Memorial Lecture. Dictada en la Universidad de Sydney.

Klein, N. (2008). La doctrina del shock. El auge del capitalismo del desastre. Argentina: Paidós.

Kuhn, T. (1995). La estructura de las revoluciones científicas. México: Fondo de Cultura Económica.

Laffaye, S. (diciembre, 2008). La crisis financiera: origen y perspectivas. Revista del CEI, (13).

Lander, L. E. y López, M. (1999). Venezuela. La victoria de Chávez. El polo Patriótico en las elecciones de 1998. Nueva Sociedad,(160). Recuperado de: www.nuso.org/upload/articulos/2749_1.pdf

Martínez, J. H. (2014). El papel del Movimiento Quinta República en la recomposición del Estado Venezolano (1998-2000). Historia actual online, (33), $21-34$.

Martínez, J. H. (2008). Causas e interpretaciones del caracazo. Historia Actual Online, (16), 85- 92.

Martínez, L. y Herrera, L. (s. f.). Ejército Popular Revolucionario (EPR): Entre el viejo y el nuevo paradigma de lucha. En Estudios sobre la diversidad. Sergio Sánchez Vázquez (Coordinador). México: Universidad Autónoma del Estado de Hidalgo, Plaza y Valdés. En imprenta.

Montaner, C. A. (2012). El más práctico de todos los teóricos”. En Milton Friedman un liberal influyente. Chile: Libertad y Desarrollo.

Morales, E. (2011). Prólogo, en Vivir Bien ¿̨Paradigma no capitalista? Ivonne Farah H y Luciano Vasapollo (Coordinadores). Bolivia: CIDES-UMSA, Sapienza, Oxfam. 
Muñoz, D. y Marín,D. (2012).E. Dusselexplica la teoría ElGiro Descolonizador [video]. Recuperado de: https://www.youtube.com/watch?v=mI9F73wlMQE

Mutis, G. (2013). Valor compartido, una estrategia empresarial de alto impacto. Tendencias/ empresa. Recuperado de: www.liderazgoygestion.com/articulos_ gm/valorcompartido.pdf

Ontaner, C. A. y otros (2012). Milton Friedman. Un liberal influyente. Recuperado de: www.lyd.com/wp-content/uploads/2012/11/Documento-FRIEDMAN.pdf

Ornelas, J. (2001), El neoliberalismo realmente existe. México: Pensamiento Económico.

Porter, M. y Kramer, M. (2011). La creación del valor compartido. Harvard Business Revierw. América Latina. Estados Unidos: Harvard.

Samour, H. (2014). Aspectos ideológicos del paradigma neoliberal Revista realidad. Recuperado de: www.uca.edu.su/revistarealidad archivo/4ddd8c55ccf14aspectosideologicos.pdf

Sautu, R., Boniolo, P., Dalle, P. y Elbert, R. (2005). El análisis crítico de investigaciones como insumo para el diseño de un proyecto de investigación. Buenos Aires: CLACSO.

Serrano, B. (2011). La rebelión de los estudiantes de Harvard contra la enseñanza neoliberal: Un mensaje al mundo sobre la encrucijada de la Economía. En Crisis del XX. Recuperado de: http://crisisdelxxi.blogspot.mx/2011/11/ la-rebelion-de-los-estudiantes-de_30.html

Solimano, A. (2013). Neoliberalismo: Orígenes, influencia y crisis", CIGLOB, 2(4). Recuperado de: http://ciglob.org/inicio/files/Newsletter\%2oCiglob\%20 Mayo\%202013\%20N\%C2\%B04\%20Vol\%202(1).pdf

Somuano, M. F. (2007). Movimientos sociales y partidos políticos en América Latina: una relación cambiante y compleja. Política y cultura, (27), 3153. Universidad Autónoma Metropolitana Unidad Xochimilco: Distrito Federal, México.

Tanzi, V. (2010). La crisis financiera y económica de 2008-2009: Efectos fiscales y monetarios. Ponencia en el XXXVII Seminario Internacional de Presupuesto Público, Madrid, del 5 al 8 de julio de 2010. Recuperado de: www 10.iadb. org/intal/intalcdi/PE/2011/08050.pdf 
Tarrow, S. (2004). La sociedad en movimiento. Los movimientos sociales, la acción colectiva y la política. Madrid: Alianza.

Von Werlhof, C. (2011). La globalización del Neoliberalismo, sus efectos y algunas alternativas. Theomai, (23). Recuperado de: revista-theomai.unq.edu.ar.

Zuazo, M. (2010). ¿Los movimientos sociales en el poder? El gobierno del MAS en Bolivia. Nueva Sociedad, (227). Recuperado de: www.nuso.org/upload/ articulos/3700_1.pdf

Zurita, J., Martínez, J. F. y Rodríguez, F. (2009). La crisis financiera y económica del 2008. Origen y consecuencias en los Estados Unidos y México. El Cotidiano, (Septiembre- Octubre), 17-27. México: Universidad Autónoma Metropolitana Azcapotzalco. 